Sultan Qaboos University Journal of Arts \& Social Sciences

جامعة السلطان قابوس الأوداب مجلة الآداب والعلوم الاجتمأعية

\title{
Readiness of Public and Private Sector Organizations for Knowledge Management: A Literature Review
}

\begin{tabular}{c}
\hline Hamyar Nasser Al-Mahruqi \\
\hline State Andit Institution \\
Sultanate of Oman \\
hnalmahruqi@sai.gov.om
\end{tabular}

\begin{tabular}{c}
\hline Abdelmajid Bouazza \\
Tunisia \\
bouazza93@gmail.com
\end{tabular}




\title{
Readiness of Public and Private Sector Organizations for Knowledge Management: A Literature Review
}

\author{
Hamyar Nasser Al-Mahruqi, Abdelmajid Bouazza and Mohammed Nasser Al-Suqri
}

\section{Abstract:}

This paper reviews the growing literature on organizational readiness for knowledge management (KM) in both public and private sectors. It is based on literature published during the period 1997-2016. Only original research papers have been included in this literature review. The thematic structure has been adopted. In the beginning, significance of knowledge as well as the significance and definition of KM will be clarified. Afterwards, the underlying problems and methodological issues raised in the literature will be discussed. The paper also reviews the relationship between organizational readiness and organizational and human contributing factors. Finally, significant differences in employees' attitudes and willingness to be involved in the KM process according to different demographic variables will be examined. Research shows that it is essential to assess organizational readiness before embarking on KM projects. In addition, research indicates that both organizational factors, namely, culture, structure, and information technology (IT) infrastructure, and human factors, namely, acceptance of $\mathrm{KM}$ and willingness to participate in the KM process influence, organizational readiness for KM. This study is useful for researchers and practitioners to understand current trends and problems and methodological issues. This paper identifies trends, problems and methodological issues. A mixed-approach investigation consisting of both quantitative and qualitative methods is recommended to provide a comprehensive understanding of the contributing factors influencing organizational readiness for KM.

Keywords: Knowledge Management; Readiness; Organizational Factors; Human Factors; Public Sector; Private Sector; Literature Review.

\section{جاهزية مؤسسات القطاعين العام والخاص لإدارة المعرفة: مراجعة الإنتاج الفكري}

حمير ناصر المحروقي، وعبدالمجيد بوعزة، ومحمد ناصر الصقري

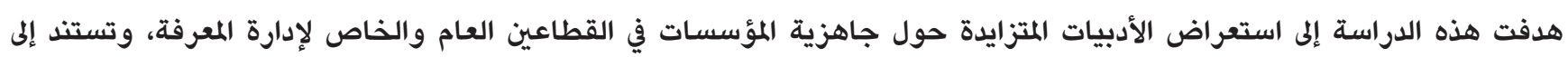

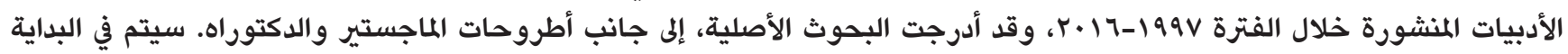

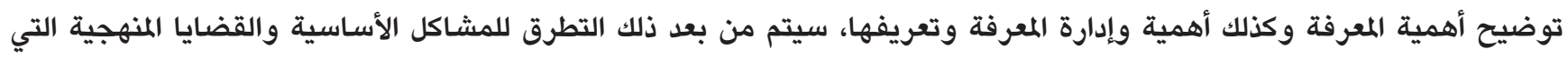

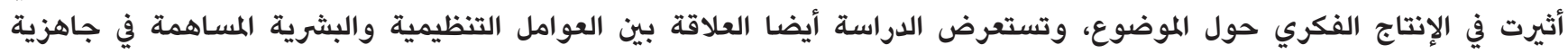

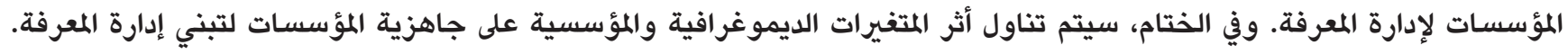

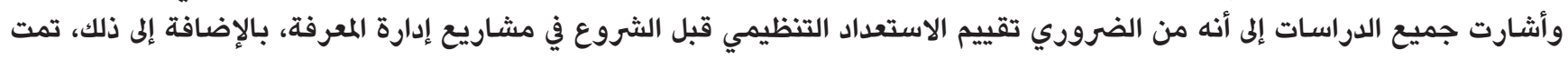

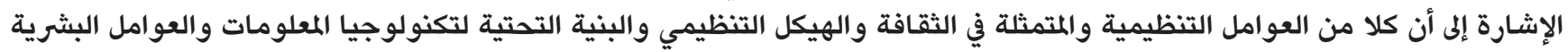

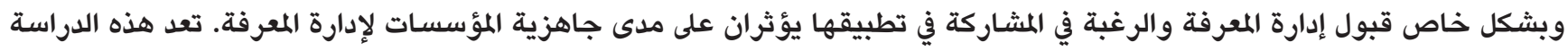

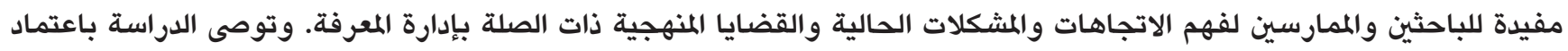

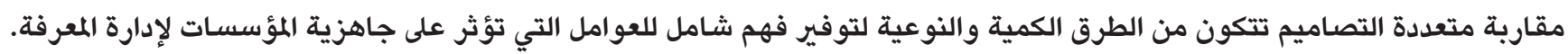




\section{Introduction}

Knowledge is a major component of success for different organizations (Ghorbani, 2016). Uriarte (2008) argued that organizations should pay close attention to knowledge, since it is more important than other assets such as land, labor, and capital. Nejadhussein and Zadbakht (2011) highlighted that knowledge can be a very important resource in helping organizations to achieve their goals and objectives if it is managed effectively. Nonaka and Takeuch (1995) made the point that organizations can be successful if they are capable of creating new knowledge, disseminating it, and embodying it in its products and services. They indicated that creating new knowledge fuels innovation.

Based on that argument, it is recognized that the possession of knowledge is not a goal in itself but a tool for performing job responsibilities effectively and, therefore, achieving objectives efficiently. To achieve this goal, organizations are facing the challenge of developing and maintaining the ability to manage knowledge efficiently.

In practice, KM is the identification of intellectual assets, generating new knowledge for the purpose of competitive advantage, making common information accessible, sharing the best practices, and employing technology to achieve these objectives (Barclay and Murray, 1997).

Uriarte $(2008$, p. 24) provided a very simple definition of KM. He defined it as "the conversion of tacit knowledge into explicit knowledge and sharing it within the organization". He phrased this definition more technically by defining KM as "the process through which organizations generate value from their intellectual and knowledge based assets" (Uriate, 2008. P. 24).

According to Nejadhussein and Azadbakht (2011), $\mathrm{KM}$ is one of the solutions to assist organizations in avoiding failure, meeting challenges, as well as enhancing learning competencies. They argued that the first step is to determine the organization's readiness before starting any KM application.

Readiness is a condition for any organization that intends to implement the KM process. Razi and Abdul Karim (2010, p. 323) defined readiness for KM process implementation as "the intention to be involved in the KM process by the organizational individuals within the prevailing organizational context".

Therefore, this study aims to review the literature available in English and Arabic on readiness of organizations to implement the knowledge management (KM) process. First, it considers studies related to readiness of organizations for KM process implementation. This part covers studies discussing enablers of KM in general, and organizational culture, structure, and IT factors in particular. Second, it browses studies focused on knowledge management maturity models (KMMM). Then, the focus turns to reviewing studies discussing employees' acceptance of KM. After that, it sheds light on studies related to employees' intention to be involved in the KM process. Next, it highlights demographic factors influencing employees' adoption and intention to be involved in the KM process. In addition, it reviews studies related to influential factors in KM process adoption and implementation.

\section{Objective of the study:}

Explore the influence of organizational and human factors on KM process adoption and implementation.

\section{Research questions:}

1. To what extent do KM enablers, namely, organizational culture, organizational structure, and IT infrastructure, affect the readiness of private and public organizations to implement KM processes?

2. What are the main contributions of selected knowledge management maturity models?

3. What are the expectations of employees towards KM?

4. To what extent does the employees' willingness to be involved in the KM process affect the success of organizations in implementing KM?

5. What is the impact of demographic factors on employees' adoption of and intention to be involved in the KM process?

6. What are the motivating and impeding factors for KM process adoption and implementation?

\section{Limitations of the study:}

Time Limitation: this paper is based on the literature published during the period 1997-2016.

Language Limitation: this study reviews the literature available in English and Arabic, therefore, papers published in any other language were not included. Information resources limitation: this study covers only studies based on a scientific methodology. Therefore, opinion-based works have been excluded.

\section{Significance of the study:}

It incorporates both organizational and human factors affecting organizational readiness for $\mathrm{KM}$ 
implementation. Therefore, it enables private and public organizations to assess their readiness for KM process implementation.

\section{Definition of the concepts:}

1. Organizational readiness for KM process implementation: willingness of organizational members to be involved in the KM process supported by an appropriate organizational culture, structure and IT infrastructure as well as employees' acceptance of KM in order to enable the organization to adopt and benefit from KM.

2. Effort expectancy of KM: individuals' expectations about required effort when involved in the KM process.

3. Performance expectancy of KM: individuals' expectations about the benefits of KM for their job performance.

7. Measuring organizational readiness for KM process implementation:

The first category of the literature will include four groups of studies. First, it will review key studies that have investigated the readiness of organizations for KM process implementation. Then the different cultural, structural, and IT factors influencing the readiness of organizations for KM process implementation will be reviewed separately.

7.1 Key studies measuring organizational readiness for KM process implementation:

In order to measure the readiness of an Air Force agency to implement KM, Holt et al. (2007) reviewed the literature to develop an appropriate instrument which was designed to determine the employees' thoughts regarding their readiness for change. The study aimed to investigate the relationship between KM attitudes and five subscales representing the following facets of KM readiness: individual measures, context measures, content measures, process measures, and KM attitudes. A questionnaire was completed by 146 civilian and military personnel of various grade levels, with results reflecting that their attitudes towards KM exhibited strong relationships with the majority of the individual, context, content and process variables. For instance, pessimism was positively related to individual characteristics including negative affect, innovativeness and negatively related to other individual, context, content and process variables. Furthermore, the results reflected a negative relationship between affective commitment, which measured the participants' commitment to provide support for KM initiatives, and negative affect and innovativeness respectively. Meanwhile, it was positively related with all other study variables. Finally, the results revealed that the individual and context variables - which are deeply rooted in the organization's fabric - are influential and difficult to change.

Mohammadi et al., (2009) extracted eighteen success factors from the literature. They intended to assess the readiness of an IT firm in Iran. The factors were categorized into the following five groups: culture of knowledge, structure, support for change, infrastructure, and vision for change. The results indicated that infrastructure and culture of knowledge scored highest on readiness. All of the measures for these two groups recorded high scores. In addition, the results suggested that readiness according to some measures for the other three groups was at a medium level (such as education, management support, and reward system). Therefore, attention should be paid to these aspects in order to achieve readiness for KM. The study suggested that more focus should be given to people and culture because many KM projects that had solely emphasized technology had failed.

Razi and Abdul Karim (2010) conducted an intensive review of KM literature related to assessing organizational readiness for KM process implementation. They identified some research gaps in this area. Therefore, they proposed a basic research model and instrument to enable organizations to assess their readiness for $\mathrm{KM}$ process implementation. The research model was based on two theories, namely, the theory of reasoned action and the theory of planned behavior. It was also founded on various frameworks which were developed based on the theory of knowledge creation and the KM enablers. In addition, it considered individual characteristics. They found that it can be assumed that employees' intention to be involved in KM process implementation can be influenced by KM enabling factors, namely, organizational culture (OC), organizational structure (OS), and IT support (ITS). In addition, individual acceptance of KM as well as moderating factors such as gender and age can be considered as contributing factors.

A study based in the Gulf States that attempted to explore the factors affecting organizational readiness for KM was conducted by Al-Bastaki and Shajera (2012). They aimed to examine the readiness of three aspects of KM infrastructure, namely, organizational 
culture, structure, and IT infrastructure within the University of Bahrain. The results revealed that all of the seven variables, namely, collaboration, trust, learning, centralization, formalization, reward systems, and IT support are significant and need to be promoted by the university. The findings indicated that such promotion would require changes to the university's culture and structure. In addition, the results reflected a high to medium readiness level for two variables, namely, IT support and reward system, while a medium to low level of readiness was indicated for the other five variables. The study suggested several ideas for promoting $\mathrm{KM}$ infrastructure at the university, for example, promotion of trust and collaboration as well as shifting from a hierarchal to a horizontal structure.

To investigate the concept of KM readiness, Abdul Karim et al. (2012) conducted an empirical study. They used the concept of intention to be involved in the KM processes of socialization, externalization, combination, and internalization (SECI). The results revealed that all variables of intention to be involved in $\mathrm{KM} \mathrm{SECl} \mathrm{processes} \mathrm{were} \mathrm{significant} \mathrm{measures} \mathrm{for}$ KM readiness. The study suggested that organizational readiness for $\mathrm{KM}$ process implementation can be assessed by investigating the influence of organizational culture, structure, IT, and other human attributes on employees' intention to be involved in KM process implementation.

Shahidi et al., (2015) tested six hypotheses, assuming that six factors, namely, organizational culture, individual, IT infrastructure, knowledge process, strategy, and senior management commitment would have effects on organizational readiness for KM implementation in three different organizations representing IT services, education and commerce. The results revealed that the effect of culture was rejected in all organizations, while IT infrastructure and senior management commitment effect was confirmed in the educational and commerce organizations. It was found that those two factors had a negative effect on the IT organization. Moreover, the results indicated that the knowledge process had an effect on the commerce organization, while it had negative effects on the other two organizations. The negative effect was due to the lack of documented processes and procedures to access the required knowledge as well as a lack of knowledge workers. Finally, the study suggested that organizations should promote employees' technical skills in the use of information systems through classes and workshops.
Kamaruzzaman et al., (2016), meanwhile, conducted an empirical study to assess the readiness of Malaysian facilities management (FM) organizations to implement KM systems. Interviews were conducted among key FM staff at one of the country's technology institutes to determine factors influencing success in $\mathrm{KM}$. A questionnaire consisting of ten critical success (CSF) factors, namely, leadership, culture/structure, processes, explicit knowledge, tacit knowledge, knowledge hubs, technology infrastructure, measure, exploitation, and people/skills, was used as a basis for interviews. The results revealed that of the ten CSF there were only two for which Malaysian FM organizations were not prepared, namely, leadership and measurement. It was interpreted that FM organizations have no specific strategy for storing and managing $\mathrm{KM}$ at a significant level. In addition, assessment of the contribution of the existing knowledge is poor. On the other hand, eight CSF passed the standard score of readiness. To illustrate, people and skills achieved the standard score. This is interpreted as meaning that these organizations understand that their success depends on their employees' knowledge. Finally, the results indicated that technology infrastructure was formally managed in such a way as to link employees efficiently.

One of the most recent studies investigating $\mathrm{KM}$ initiatives and studying the factors impacting these initiatives was conducted by Patil (2016). A descriptive research design was followed to explore the impact of four factors, namely, management initiatives, organizational culture, ICT adoption and employee participation in KM initiatives. An overview of twenty previous studies showed that organizational culture, particularly trust and collaboration, as well as ICT influence KM initiatives. The results revealed that the four factors have a positive impact on KM initiatives. In addition, they indicated that management initiatives including motivation, support of subordinates, training programs, and dynamic reallocation of resources and absence of bureaucracy were major factors in fostering KM in the business schools studied. Moreover, ICT implementation was found to enable knowledge transfer and sharing among stakeholders. Finally, the study recommended that schools develop an overall organizational culture of socialization, externalization, combination, and internalization of both tacit and explicit knowledge.

\subsection{Organizational culture factors:}

Alkaf (2010) conducted a study to investigate the 
existence of knowledge society requirements in Omani universities. The results revealed that the requirements related to the university's vision to achieve a knowledge society had the highest level of availability. He attributed this result to the high awareness of the universities of the importance of the concept of knowledge society.

Salleh (2010) investigated the relationship between KM enablers and tacit KS processes. He presented a KS model that connected KM enablers and KS processes in a public sector organization in Malaysia. The problem statement of the study was how to convert individuals' tacit knowledge into organizational explicit knowledge. He recorded the perceptions of 203 accountants working in the Accountant General's Department of Malaysia towards the influence of four factors on KS performance. These factors included learning, leadership, technology, and culture. The results revealed that two variables, namely, performance evaluation and incentives, had a highly significant impact on tacit KS performance, while other factors had a moderate impact. The study suggested that leaders should encourage collaboration and team learning as well as providing an appropriate climate for KS. In addition, it was recommended that promotional and reward systems should be established to encourage KS.

Masrek et al., (2011) identified relationships between four dimensions of cultural identity, namely, horizontal individualism, vertical individualism, horizontal collectivism, and vertical collectivism and KS behavior, among university students in Malaysia. The results indicated that the vertical collectivism dimension influenced KS behavior, whilst all dimensions existed among the students. In addition, Pearson's correlation tests showed that both collectivism variables correlated significantly with KS behaviors. In other words, students believe that KS and group work enhance innovation.

In another study, Aljaaferah (2012) investigated the impact of KM in the Ministry of the Interior in Jordan. He indicated that incentives and training are the key to encourage employees to adopt and implement KM. Abdul Karim et al. (2012), found that trust and collaboration are both strong predictors of KM and essential to facilitating successful implementation of $\mathrm{KM}$; therefore, they need to be emphasized. Furthermore, it is necessary to conduct training programs to ensure awareness and understanding of the benefits of KM. Finally, reward systems should be established to encourage employees to engage in KM before it is embarked on.

Pinho et al., (2012) reviewed and analyzed 63 papers to identify the barriers and facilitators to KM processes. They highlighted that organizations should focus on facilities, rewards, positive leadership, and recognizing performance. To illustrate, recognizing and rewarding KS, rewarding publishing, facilitating a culture of risk taking and learning from failures will enhance the KM culture. In addition, it was indicated that if organizations want to be successful in KM implementation they should promote education and learning. Moreover, the study indicated that trust and cooperation with others are important facilitators to KM processes.

In her Ph.D. thesis, Jawharah (2014) used a questionnaire to investigate perceptions of 343 employees from different Algerian hotels on the impact of strategic management on KS. The results revealed that the employees expressed moderate behavioral intention towards KS. In addition, employees indicated that their organizations have policies to motivate their KS initiatives. Furthermore, the study highlighted that the employees' behavioral intention towards KS was motivated by certain factors. These factors were the desire to help others, persuading colleagues of the skills they possess, and enjoying helping colleagues. The results also showed that there was a strong relation between strategic management practices and KS behaviors. To illustrate, strategic management practices encourage hotels to adopt KS strategies. In addition, the study found that organizational learning culture had a strong impact on KS behaviors and KS strategies. In other words, the existence of an organizational learning culture supported the adoption of KS strategy by these hotels. In a comprehensive guideline, the Ministry of Public Sector Development in Jordan reviewed the essential organizational factors for supporting KM in public organizations. It stressed that a supportive organizational culture should be adopted to enhance KS among employees. Therefore, pubic organizations should establish mechanisms to enhance KS. In addition, all barriers facing KS should be removed. Furthermore, training is important to support KM. The guideline also mentioned the importance of motivating employees to use and to share knowledge. Moreover, the guideline identifies top management support as one of the requirements to guarantee KM success in public organization (Development, 2015). 


\subsection{Organizational structure factors:}

Alhasmi (2011) indicated that knowledge creation and sharing requires creativity. She argued that organizations that adopt centralization in KM hinder creativity. Decentralization, however, enables individuals to share the required knowledge and then implement it in performing tasks.

The Jordanian Ministry of Public Sector Development indicated that knowledge creation requires a high level of decentralization and informality. To illustrate, knowledge creation is impeded when decisionmaking authority is limited to top management and organizations strictly adhere to work rules (Development, 2012).

Pinho et al., (2012) identified decentralization as a very important factor impacting KM processes. It improves functional communication, thereby enhancing the level of knowledge flow.

Alkharoosi (2015) investigated the factors influencing academics' behavioral intention towards KS. She found that organizational charts had little or no effect on academics' behavioral intention towards KS.

\subsection{IT infrastructure factors:}

Alkaf (2015) mentioned that IT is the most effective enabler for knowledge society. He added that the knowledge era imposes the use of IT tools. Therefore, it is difficult to achieve a knowledge society without appropriate IT infrastructure.

Salleh (2010) stated that IT should enhance the process of KS by supporting tacit and explicit knowledge capture. The results of the study revealed that IT had a moderate impact on KS performance.

In a master's thesis, Alajmi (2011) investigated the impact of KM implementation on the participation of workers in the telecommunications sector in decision-making. He assumed that technology would have no significant impact on workers' participation in decision-making. The results revealed that there was a significant relation between technology and workers' participation in decision-making as well as an impact on all stages of decision-making.

Abdul Karim et al., (2012) investigated the significance of IT in KM adoption. The results indicated that IT support and ICT use and support were key predictors of KM adoption as well as strong predictors of intention to be involved in the KM process. In addition, IT was highlighted as the backbone of any organization. It was also pointed out that ICT use is essential to facilitating successful implementation of $\mathrm{KM}$. Therefore, IT is a very important factor in terms of influencing employees' intention to be involved in the KM process.

Algahwari (2015) also indicated that IT has a major role in $\mathrm{KM}$. In addition, he pointed out that, in turn, it coordinates with other resources, particularly human resources. He mentioned that IT enhances the ability to manage existing knowledge. Moreover, it enhances not only interaction between human resources but all the KM processes. He stated that the ministry of education pays close attention to implementing IT for the purpose of communication between employees.

The Ministry of Public Sector Development in Jordan highlighted that appropriate technological infrastructure is essential to support KM. It identified many essential elements that include intranet and document electronic library, information security policy, efficient computers and servers, fundamental software (archiving, financial, and human resources systems), and advanced systems such as simulations and artificial intelligence programs (Development, 2015).

\section{KM maturity models:}

The competence center for $\mathrm{KM}$ at Siemens $\mathrm{AG}$ developed a methodology lead to understand and appreciate development of KM. As reported by Ehms and Langen (2002), this methodology was called KMMM. They also stated that such methodologies enable organizations to find the most appropriate starting point before the actual start of KM. They further identified that the first step in developing professional KM is to determine the current practiced activities and organizational conditions. The model consists of the following five maturity levels: initial, repeatable, defined, managed, and optimizing.

Hung et al., (2005) proposed a model consisting of two different types of representation. The first, stage representation was called the KM pyramid model, whilst the second, continuous representation, was called the KM readiness model. This dual representation model aims to find out what capabilities an organization possesses as well as to identify the improvements that need to be considered. In addition, it aims to assess differences in KM practices among organizations. The model consists of three components, namely, maturity levels, KM processes, and KM capabilities or enabling infrastructure. The model follows the above mentioned Ehms and Langen (2002) classification of maturity into consisted of five levels. With regard to KM capabilities it focuses on three key enabling infrastructure elements: structural, 
cultural, and technical. The KM readiness model focuses on KM processes that have been adopted by an organization as well as KM infrastructure that has been incorporated. Finally, the authors stated that an organization reaches a particular maturity level when its KM practices meet the objectives of that level.

The American Productivity \& Quality Center (APQC) designed a comprehensive assessment tool based on five levels of KM maturity. These levels comprise initiate (growing awareness), develop (localized and repeatable practice), standardize (common process and approaches), optimize (measured and adaptive), and innovate (continuously improving practices). The assessment tool was designed in 2010 to enable organizations to measure their KM programs. The designers argued that KM programs need to be measured in order to find out how mature they are. The capability assessment tool (CAT) consists of the following four broad categories: strategy (objectives, business case, budget), people (resources, governance and leadership, change management, communication), process (knowledge flow process, KM approaches and tools, measurement), and content and IT (content management process, IT). It is indicated that CAT enables organizations to understand how far their KM programs have come, how far they have to go to reach the maximum efficiency, and on what capabilities they need to focus in order to move forward. Finally, the APQC claimed that the results of CAT enable organizations to make strategic decisions about the future of their KM programs (American Productivity \& Quality Center, 2011).

Baykiz (2014) developed a knowledge management maturity model (KMMM) by studying the existing models. He argued in his master's thesis that the proposed model can be used in the public sector. The proposed model incorporates people, process, and technology as the three main process areas. In addition, it covers five maturity levels, namely, initial, aware, defined, managed, and continuously improving. Movement from one level to another indicates that the organization has made improvements in terms of KM.

\section{Employees' acceptance of KM:}

Abdul Karim et al., (2012) mentioned that employees' acceptance needs to be assessed before organizations make any commitment regarding KM initiatives. Such acceptance indicates the organization's readiness for KM process implementation. Since the study aims to identify employees' expectations of KM, the following part will review studies that have discussed this aspect.

Abdul Karim et al., (2012) investigated the influence of expectancy of KM among Sri Lankan telecommunication executives. The results showed that respondents had high expectations of KM. To illustrate, they expected that they would benefit from $\mathrm{KM}$ and that it would be easy and require little physical and mental effort to engage in the KM process. In addition, the results revealed that performance and effort expectancy of KM were key and strong predictors of intention to be involved in KM process. Effort expectancy of KM was the strongest predictor followed by performance expectancy of KM.

Nasr et al., (2013) studied the impact of attitudes towards KS on employees' happiness in a university in Iran. They argued that managers should keep employees happy in order to enhance organizational productivity. The results revealed that employees' attitudes towards KS have an effect on their happiness. In addition, the findings indicated that motivation for KS has an effect on employees' happiness. Moreover, it was found that obstacles to KS for others have an effect on employees' happiness. To sum up, when attitudes towards KS are enhanced, the employees' happiness is increased, which will affect organizational productivity positively.

Another study investigating employees' expectation of one of the KM processes was conducted by Asderaki and Samul (2015). Employees in six large public organizations participated to express their attitudes towards the importance of acquiring knowledge and using their competencies in their work. The results revealed that employees are aware of the role they play and find it important to use their full competencies at work. In addition, the findings showed high expectations of employees in relation to knowledge acquisition opportunities. To illustrate, public organizations should prepare an appropriate climate for knowledge acquisition in order to enhance employees' capabilities and thereby support organizational productivity.

Pee and Kankanhalli (2016) conducted an exploratory study to identify factors influencing $\mathrm{KM}$. The results revealed that organizational effectiveness is influenced positively when KM capability is improved. In other words, when employees have capability to implement KM organizations are influenced accordingly.

One of the most recent and relevant studies on employees' performance expectations of KM was conducted by Kulkarni (2016). It explored expectations 
of KM systems among IT faculty members and IT heads in business schools in India through questionnaire and interviews. The author argued that employees' perceptions of KM should be considered before starting any KM practice. The results revealed that improving employees' efficiency as well as improving their skills and knowledge were the most significant expectations related to performance. Moreover, they expected that KM would increase decision making ability as well as preventing duplication of work. Finally, they believed that KM would improve employees' involvement in their work activities.

\section{Employees' intention to be involved in KM process:}

Salleh (2010) argued that good organizational infrastructure and IT infrastructure will not lead to development of good knowledge assets in any organization if the employees' willingness to share their tacit knowledge is lacking.

Okyere-Kwaye and Nor (2011) indicated in their conceptual study that employees' behavior depends on their intentions and willingness towards KS. They pointed out that the literature indicates a lack of willingness among employees to participate in KM in general and KS in specific. Finally, they argued that achieving success in one's job responsibilities requires high recognition of the importance of KM.

Abdul Karim et al., (2012) investigated the intention of 313 executives in the Sri Lankan telecommunication industry to be involved in the KM process and their study found that willingness of employees to be involved in one or all KM SECl processes is a good indicator of organizational readiness for $\mathrm{KM}$. In addition, the results showed a positive level of intention among respondents to be involved in KM $\mathrm{SECl}$ processes. Therefore, these findings indicate that the Sri Lankan telecommunication industry is ready for KM process implementation.

Abdulaal (2014) found that the willingness of top and middle management to adopt different research strategies to create new knowledge as well as their ability to use a variety of knowledge resources enhanced their knowledge creation behaviors.

One of the recent studies investigating the relationship between $\mathrm{KM}$ and employees was conducted by Ghorbani (2016). He found evidence of a significant relationship between $\mathrm{KM}$ and employees' empowerment in an agricultural bank in Iran. In specifically, there is a relationship between $\mathrm{KM}$ and all empowerment dimensions (self-esteem, self-organization, feeling of effectiveness, selfeffectiveness, and feeling of being significant). In other words, employees' empowerment is influenced by the KM situation. KM is considered an antecedent of employees' empowerment. It is also pointed out that participation among organizational members can be enhanced by improving employees' abilities and cooperation in different activities in organizations.

11. Demographic factors influencing employees' adoption and intention to be involved in $\mathrm{KM}$ process:

The following part of the literature review will discuss the role of some demographic variables in employees' attitudes towards KM enablers, employees' acceptance of $\mathrm{KM}$, as well as in their intention to be involved in the KM process.

Alkaf (2010) pointed out significant differences in attitudes towards the availability of knowledge society requirements relating to the University of Nizwa in Oman. It can be interpreted that the university pays most attention to the concept of knowledge and having a clear vision of the knowledge society. The study also identified significant differences in relation to the job of academic leader. It was interpreted that this category of staff have precise knowledge of the latest developments related to the provision of knowledge management society compared to faculty staff. Finally, the study pointed out significant differences relating to the level of work experience.

Almansoori (2011) conducted a master's thesis to investigate differences between demographic variables among academicsat Sultan Qaboos University and the degree of application of KM processes by the university. The results indicated no significant differences related to gender, position, and nationality, while significant differences emerged relating to college and experience. To illustrate, academics with long experience believed more in the importance of KM. The study suggested that awareness about the concept of KM and its importance as well as the best practices of KM should be promoted, potentially by training programs, workshops, and symposiums.

Albalushi (2011) determined the relationship between certain demographics of employees and barriers to KM implementation in the Ministry of Education in Oman. The results revealed that those in high job positions had significantly different attitudes towards the implementation of KS. Meanwhile, the study revealed no differences related to educational 
level. With regard to barriers, the results revealed no differences in attitudes towards the presence of barriers impacting $\mathrm{KM}$ implementation in terms of job title. On the other hand, the results indicated that educational level had an impact on attitudes towards barriers. To illustrate, employees holding a bachelor degree were more influenced by barriers compared to diploma holders.

Albarashdi (2012) determined the impact of demographic factors on KS among managers in Omani industrial enterprises. She found that whilst gender had no impact on KS, experience and educational level influenced KS positively. To illustrate, managers holding high qualifications or who had long experience were more active regarding KS processes.

Alajmi (2011) found no significant differences between the work environment culture and technology as dimensions of $\mathrm{KM}$ in relation to gender, position, and work experience. On the other hand, the results highlighted significant differences related to age and educational level. The study suggested that IT infrastructure should be enhanced and drew attention to the importance of KM for all employees regardless of their years of experience and educational level.

One of the most relevant studies was conducted by Razi et al., (2014a). They analyzed the factors moderating relationships contributing to executives' intention to be involved in the KM process in Sri Lankan telecommunication industries. The results revealed that, while demographic factors including age, experience, and management level had no moderating effect on any relationships, gender differences had a moderating effect on the relationship between (ICT use and support for searching and sharing) and intention to be involved in KM process among females when compared to males. To illustrate, extensive use of ICT and support for searching and sharing encouraged females more than males to be involved in the KM process. Similarly, the perceived usefulness of the KM encouraged females more than males to be involved in KM process. Therefore, the study suggested that possible gender differences should be considered by policy makers when planning to implement KM initiatives and when making policies, especially in regard to IT.

12. Influential factors for KM process adoption and implementation:

The studies reviewed in this category all focus on factors of KM process adoption. Studies on motivating factors will be reviewed first, followed by a review of previous studies discussing impeding factors.

12.1 Motivating factors for KM adoption and implementation:

A holistic study to investigate the impact of culture, leadership, organization structure, employee participation, and information and communication technology as factors influencing the KM process was conducted by Tan (2011). The study also aimed to determine the level of acceptance of KM and to highlight the importance of KM and its contribution to small and medium enterprises (SMEs) in Malaysia. The results indicated that SMEs in Malaysia are unable to take full advantage of KM. Further, there were significant correlations between all success factors and KM processes. It was noticed that the results did not include the impact of demographic characteristics on attitudes towards success factors.

Al-Hakim and Hassn (2011) clarified the core requirements of $\mathrm{KM}$ implementation which lead to improved organizational performance. They found that the literature identified seven critical factors (CSFs) of KM: human resource management, IT, leadership, organizational culture, organizational structure, organizational learning, and organizational strategy. They proposed a model to explain relations between these core requirements and organizational performance.

Albarashdi (2012) found that top management support and moral and financial incentives were the most critical factors influencing KS among industrial enterprises in Oman. In addition, the results revealed that IT played a major role in enhancing KS. Moreover, it was found that KS was influenced positively by many motivating factors, including problem solving, improving the efficiency of human resources, and promoting the industrial sector in the country.

Arabshahi et al., (2013) conducted an exploratory study to examine the impact of four emotional intelligence factors on KS behavior among faculty members of different Iranian universities. Qualitative data was collected through interviews, while quantitative data was collected through questionnaire. The results revealed that three emotional intelligence factors, namely, social skills, overall creation, and coping with pressure, had an impact on faculty members' KS behavior. On the other hand, findings indicated that there was no significant relationship between adaptability and KS behavior.

Abdulaal (2014) found that top and middle management in Jordanian industries had a high 
interest in knowledge creation because of the motivating work environment. To illustrate, the work environment supported knowledge creation through an incentive system as an important factor in developing knowledge capital.

In her master's thesis, Alkharoosi (2015) identified the behavioral intention toward KS of academics in the college of science at Sultan Qaboos University. She determined the effect of intrinsic and extrinsic motivations, barriers to $\mathrm{KS}$, and organizational climate. The results indicated that academics' behavioral intention towards KS was strongly influenced by certain variables. These variables were self-esteem, competitive advantage, trust, communication, leadership support, and information and communication technology. The study suggested that a financial and moral rewards system should be promoted to encourage academics to share knowledge.

Pee and Kankanhalli (2016) identified factors influencing KM in 101 public organizations. The results indicated that $\mathrm{KM}$ is supported by many factors, including senior management championship, social capital, and employees' job expertise. Among these factors, senior management championship has the strongest enhancing impact.

\subsection{Impeding factors for $\mathrm{KM}$ adoption and} implementation:

Taylor and Wright (2004) investigated factors influencing readiness for $\mathrm{KS}$ in a health care organization in the United Kingdom. They aimed to find out both the impact of organizational factors on KS and whether there were unique factors influencing KS in the public sector. 132 managers completed a questionnaire consisting of 27 statements categorized into six factors, namely, open leadership climate, learning from failure, information quality, performance orientation, satisfaction with change process, and a vision for change. The results indicated that effective KS is influenced by a wide range of organizational issues and that KS will be inactive if managers do not overcome these challenges. In addition, the findings revealed that all six factors have an influence on effective KS. The study further indicated that the public sector faces several challenges regarding KS. To illustrate, the public sector culture seeks compliance rather than innovation. Also, employees lack willingness to learn from mistakes because of accountability. Meanwhile, collaboration is weak because the focus is on individual agency. Finally, the study suggested that managers should encourage KS through establishing an appropriate organizational context which is free from obstacles.

Omar et al., (2010) investigated perceptions towards $\mathrm{KM}$ practices as well as challenges facing managers in a payphone company in Malaysia. The results revealed that managers believe that $\mathrm{KM}$ practices are everybody's responsibility in the organization. With regard to challenges, the finding was that the most significant challenge is to change employees' behavior from knowledge keeping to KS. The study suggested that more attention should be paid to connecting employees with each other.

Nejadhussein and Azadbakht (2011) explored the main KM factors in a university in Iran in order to investigate the university's readiness for KM. The results revealed that the university has been weak regarding KM transformation because of several obstacles. These obstacles were classified under two categories: first, Ba elements, namely, knowledge monopolies, reward and recognition, knowledge is power, lack of space for employees to meet and share their ideas, competition between employees, and lack of interest to use IT, and second, Ka elements, namely, knowledge resources, lack of relevant training programs in KM initiatives, lack of support for participating in seminars and conferences, trust, and knowledge monopolies. In addition, the findings indicated no significant differences within the faculty. In other words, KM factors were similar across the whole faculty. The study suggested that the university should establish a reward and recognition system to encourage KS and should provide a suitable environment for holding meetings among employees. Finally, the university should conduct workshops on KM.

In Oman, Albalushi (2011) identified the barriers to $\mathrm{KM}$ implementation in two departments in the Ministry of Education. The results revealed that KM implementation poses many difficulties. To illustrate, the incentive and reward system was found to be weak. This was the most critical barrier to KM implementation. Meanwhile, work overload was another barrier. Furthermore, limited top management support as well as poor ICT infrastructure influenced KM implementation negatively. The study suggested that an incentive and reward system should be established. In addition, it was recommended that awareness of the concept, practice, and importance of KM should be disseminated. Finally, KM infrastructure in general and top management support as well as ICT infrastructure should be enhanced. 
Albalushi (2012) investigated the status of KM in two commercial banks in Oman, namely, Bank Muscat and Bank Dhofar. She found that the difficulties faced by the two banks in applying KM practices can be categorized into the following three areas: social challenges to encourage creativity; management challenges to create an appropriate environment for KS; and finally, personal challenges to encourage individuals to share their knowledge with colleagues and to search for new knowledge. The results also revealed that $76 \%$ of the interviewed managers in Bank Muscat stated that they face certain issues related to KM in terms of people and IT. These consisted of technical challenges to design information systems that would help people to think together, lack of top management support, and failure in understanding the concept and benefits of KM.

To identify the impeding factors for KM implementation in industrial enterprises in Oman, Albarashdi (2012) conducted a master's thesis. A quantitative research method was used to collect the required data. The results revealed that competition was the most critical factor impeding KS, followed by lack of awareness of the concept of KS. In addition, centralization and lack of facilities posed major challenges for implementing KS.

To determine the impact of personal information overload on knowledge creation and sharing Abdulaal (2014) conducted an exploratory study. 206 top and middle managers in industrial companies in Jordan completed a questionnaire to express their perceptions. The results revealed that personal overload dimensions, namely, focus on the situation and the ability to respond to emergency situations in knowledge creation and sharing, have a significant statistical impact. The study suggested that work needs to be rescheduled to reduce the pressure on staff.

\section{Conclusion:}

The review of the literature in the area of organizational readiness for KM showed that the successful implementation of KM is influenced by many factors. Some of these factors are organizational factors, whereas others are of human nature. Some studies pointed out that trust and collaboration are the most important predictors of KM (Salleh, 2010; Aljaaferah, 2012; Pinho, and Cunha, 2012; Abdul Karim et al., 2012), whereas others indicated that incentives and reward system are more important. With regard to organization structure factors, most studies indicated that decentralization is a very important factor impacting KM. In addition, all studies (Alkaf, 2010; Abdul Karim et al., 2012; Algahwari, 2015; Development, 2012) revealed that IT plays a vital role in the KM process.

All studies (Ehms and Langen, 2002; Hung \& Chen, 2005; American Productivity \& Quality Center, 2011; Baykiz, 2014) proposed KM with five maturity levels and argued that the organizations reaches a particular maturity level when its KM practices meet the objectives of that level.

It was pointed out by some studies (Abdul Karim et al., 2011; Kulkarni, 2016) that employees' perceptions and expectations should be considered before starting any KM practice. In the same line, it was indicated that employees' willingness to participate in KM process leads to a successful implementation.

This literature review showed that only one study (Razi et al., 2013) pointed to the existence of a difference in employees' intention to be involved in $\mathrm{KM}$ process related to gender. Whereas other studies showed that there were no differences related to gender (Almansoori, 2011; Alajmi, 2011; Albarashdi, 2012; Jawharah, 2014). On the other hand, many studies found that there were significant differences related to work experience and management level for those having long work experience and high positions (Alkaf, 2010; Almansoori, 2011; Albarashdi, 2012).

Finally, most studies put supportive organizational culture as well as appropriate IT infrastructure at the top of critical success factors of KM (Tan, 2011; Al-Hakim, \& Hassn, 2011; Albarashdi, 2012; Abdulaal, 2014). Whereas the lack of incentives and reward system was the most critical barrier to KM implementation.

\section{References}

Abdul Karim, N.S., Razi, M.J.M., et al., 2012. Influential Factors of KM Process Adoption : A Socialtechnological Based Approach., 01(December), pp.95-102.

Abdul Karim, N.S. et al., 2011. Understanding Organizational Readiness for Knowledge Management in the Malaysian Public Sector Organization: A Proposed Framework. 2011 International Conference on Research and Innovation in Information Systems, pp.1-6.

Abdul Karim, N.S., Razi, M.J.M. \& Mohamed, N., 2012. Measuring employee readiness for knowledge 
management using intention to be involved with $\mathrm{KM}$ SECl processes. Business Process Management Journal, 18(5), pp.777-791. Available at: http:// www.emeraldinsight.com/journals.htm?issn=14637154 \& volume $=18 \&$ issue $=5$ \&articleid $=17053026$ sho $\mathrm{w}=\mathrm{html}$.

Abdulaal, S., 2014. The Impact of Personal Information Overload on Creating and Sharing Knowledge in Industrial Companies in Jordan. Albalqaa researches and studies, 17(1), p.30.

Alajmi, H., 2011. The impact of knowledge managementthe implementation on the Participation of Workers in Decision-Making: A Case of Telecommunications Sector in the Sultanate of Oman. Alsadaat Academy for Administration Sciences.

Albalushi, H., 2011. Knowledge Management in the Human Resources Departments and the Supervision Offices at thr Ministry of Education in the Sultanate of Oman. Sultan Qaboos University.

Albalushi, U., 2012. critical evaluation of the role of knowledge management and information technology in achieving copmpetitive advantage to the commercial banks in Oman. Middle East College.

Albarashdi, K., 2012. Knowledge Sharing Among Industrial Enterprises in the Sultanate of Oman. Sultan Qaboos University.

Al-Bastaki, Y. \& Shajera, A., 2012. Organisational readiness for knowledge management: University of Bahrain case study. Proceedings of the European Conference on Knowledge Management, ECKM, 1, pp.28-36.

Algahwari, R., 2015. Human Resource Development in The Ministry of Education in The Sultanate of Oman in The Light of The Enterance to Knowledge Management. Sutan Qaboos University.

AL-Hakim, L. \& Hassn, S., 2011. The Relationship Between Core requirements of Knowledge Management Implementation and Organizational performance. World, 3(2), pp.12-29. Available at: http://wbiaus.org/2. Laith.pdf.

Alhasmi, W., 2011. A proposed vision of a training program in the knowledge management processes for the principals of post-basic education schools in the Sultanate of Oman in light of the competency input.
Sultan Qaboos University.

Aljaaferah, A., 2012. the Impact of Knowledge Management on Organizational Performance Level in Jordanian Ministries: A Field Study of Ministry of Interior. Um Darman Islamic University.

Alkaf, H., 2010. The degree of availability of knowledge society requirements in universities in the Sultanate of Oman and ways of developing them from the perspective of academics leaders and faculty members. Alyarmouk University.

Alkharoosi, R., 2015. Behavioral intention among Academics in the College of Science at Sultan Qaboos University towards Knowledge Sharing: Application of Theory of Reasoned Action. Sultan Qaboos University.

Almansoori, A.M., 2011. The Degree of Aplying Knowledge Management Processes at Sultan Qaboos University in the Sultanate of Oman as Percieved by its Faculty Members. Yarmouk University.

American Productivity \& Quality Center, 2011. How Mature Is Your KM Program?,

Arabshahi, M. et al., 2013. The impact of emotional intelligence on faculty members' knowledge sharing behaviors. Management Science Letters, 3, pp.29632970. Available at: http://www.growingscience.com/ msl/Vol3/msl_2013_335.pdf.

Asderaki, F. \& Samul, J., 2015. THE ACQUISITION OF KNOWLEDGE IN PUBLIC ORGANIZATIONS : Abstract. International Journal of Contemporary Management, 14(2), pp.23-32.

Barclay, R. \& Murray, P., 1997. What is knowledge management. A Knowledge praxis, 20(8), pp.416-420. Available at: http://www.providersedge.com/docs/ km_articles/what_is_knowledge_management.pdf.

Baykiz, T., 2014. An Assessment of Knowledge Management Maturity Among the Public Institutions In Turkey. Middle East Technical University.

Development, T.M. of P.S., 2015. Guideline for Knowledge Management. , p.20.

Development, T.M. of P.S., 2012. Guidelines for the Application of Knowledge Management in Government Organizations. , p.40. 
Ehms, K. \& Langen, M., 2002. Holistic development of knowledge management with KMMM. Siemens AG, pp.1-8. Available at: http://www.providersedge.com/ docs/km_articles/Holistic_Development_of_KM_ with_KMMM.pdf.

Ghorbani, A., 2016. Investigating the relationship between knowledge management and employees' empowerment in agriculture bank of Tehran. Journal of Fundamental and Applied Sciences, 8(2s), pp.14291443.

Holt, D.T. et al., 2007. The development of an instrument to measure readiness for knowledge management. Knowledge Management Research \& Practice, (5), pp.75-92. Available at: www.palgravejournals.com/kmrp.

Hung, Y.H., Chou, S.C.T. \& Chen, Y.S., 2005. How can we assess knowledge management? Constructing a holistic assessment framework of KM. Proceedings of the European Conference on Knowledge Management, ECKM, pp.264-270.

Jawharah, A., 2014. The Impact of Strategic Management on Knowledge Sharing: A Case of Aljerian Hotels. Mohammad Khaidhar University.

Kamaruzzaman, S.N. et al., 2016. Assessing the readiness of facilities management organizations in implementing knowledge management systems. Journal of Facilities Management, 14(1), pp.69-83.

Kulkarni, V., 2016. Management Expectations of Indian B-Schools from Knowledge Management Systems Vaishali Kulkarni. India journal Of Reserach, 5(January), pp.86-90.

Masrek, M. et al., 2011. The Relationship between Cultural Identity and Individual Knowledge Sharing Behavior. IBIMA Business Review Journal, 2011, pp.114.

Mohammadi, K., Khanlari, A. \& Sohrabi, B., 2009. Organizational Readiness Assessment for Knowledge Management. Information Resources Management, 5(1), pp.279-295. Available at: http:// services.igi-global.com/resolvedoi/resolve.aspx?d oi=10.4018/978-1-61520-965-1.ch207.

Nasr, A. et al., 2013. Studying the Impact of Attitude towards Knowledge Sharing on Employees' Happiness (Case Study: Employees of University of Isfahan).
International Journal of Academic research in Business and social Sciences, 3(4), pp.139-150.

Nejadhussein, S. \& Azadbakht, P., 2011. Knowledge management readiness in a university in Iran. Journal of Knowledge-based Innovation in China, 3(3), pp.172-183.

Nonaka, I. \& Takeuch, H., 1995. The KnowledgeCreating Company, New York: Oxford university press.

Okyere-Kwaye, E. \& Nor, K.M., 2011. Individual Factors and Knowledge Sharing. American Journal of Economics and Business Administration, 3(1), pp.6672.

Omar, M.M. et al., 2010. Knowledge Management Perception: An Exploratory Study of a Payphone Company in Malaysia. Proceedings of Knowledge Management 5th International Conference 2010, pp.361-365. Available at: <Go to ISI >://000280416300056.

Patil, K., 2016. Knowledge Management - An Empirical Study with Special Reference to Business Schools of Pune Region. , 9(June).

Pee, L.G. \& Kankanhalli, A., 2016. Interactions among factors influencing knowledge management in public-sector organizations: A resource-based view. Government Information Quarterly, 33(1), pp.188199.

Pinho, I., Rego, A. \& Cunha, M.P. e, 2012. Improving knowledge management processes: a hybrid positive approach. Journal of Knowledge Management, 16(2), pp.215-242.

Razi, M.J.M., Abdul Karim, N.S. \& Lumpur, K., 2011. Investigating Individuals ' Intention to be Involved in Knowledge Management Process Department of Information Systems, Kulliyah of Information and Communication Technology, International Islamic University Malaysia 53100 , Jalan Gombak ,. American Journal of Economics and Business, 3(3), pp.444-449.

Razi, M.J.M., Abdul Karim, N.S. \& Mohamed, N., 2014a. Gender Difference Effects on Contributing Factors of Intention to Be Involved In Knowledge Creation and Sharing. Asian Economic and Financial Review, 4(7), pp.893-907. Available at: http:// search.proquest.com/docview/1545553104?acco untid=14719\nhttp://openurl.uquebec.ca:9003/ 
uqam?url_ver=Z39.88-2004\&rft_val_fmt=info:ofi/fm t:kev:mtx:journal\&genre=article\&sid=ProQ:ProQ:abig lobal\&atitle=Gender+Difference+Effects+on+Contrib uting+Factors.

Razi, M.J.M., Abdul Karim, N.S. \& Mohamed, N., 2013. Knowledge Management Enablers and Knowledge Management Implementation. , pp.228-233.

Razi, M.J.M., Abdul Karim, N.S. \& Mohamed, N., 2014b. Organizational Factors, Perceived Acceptance and Behavioral Intention as Dimensions of Knowledge Management Readiness.

Razi, M.J.M. \& AbdulKarim, N.S., 2010. Assessing knowledge management readiness in organizations. Proceedings 2010 International Symposium on Information Technology - System Development and Application and Knowledge Society, ITSim'10, 3, pp.1543-1548.

Salleh, K., 2010. Tacit knowledge and accountants: Knowledge sharing model. 2010 2nd International Conference on Computer Engineering and Applications, ICCEA 2010, 2, pp.393-397.

Shahidi, S., Abdolvand, N. \& Harandi, S.R., 2015. Assessing The Organizational Readiness For Implementing Knowledge Management In Organizations. International Journal of Information Technology Convergence and Services, 5(6), pp.1123. Available at: http://www.aircconline.com/ijitcs/ V5N6/5615ijitcs02.pdf.

Tan, C.N.L., 2011. Knowledge Management Acceptance: Success Factors amongst Small and Medium-Size Enterprises. American Journal of Economics and Business Administration, 3(1), pp.7380.

Taylor, W.A. \& Wright, G.H., 2004. Organizational Readiness for Successful Knowledge Sharing: Challenges for Public Sector Managers. Information Resources Management Journal, 17(2), p.22. Available at: http://proquest.umi.com/pqdweb?did $=57684470$ 1\&Fmt $=7 \&$ clientld=65345\&RQT $=309 \&$ VName=PQD.

Uriarte, F.A., 2008. Introduction to Knowledge Management, Jakarta: ASEAN Foundation. 